\title{
Distinguishing Japanese Spotted Fever and Scrub Typhus, Central Japan, 2004-2015
}

\author{
Eiichiro Sando, Motoi Suzuki, Shungo Katoh, Hiromi Fujita, \\ Masakatsu Taira, Makito Yaegashi, Koya Ariyoshi
}

\begin{abstract}
Japanese spotted fever (JSF) and scrub typhus (ST) are endemic to Japan and share similar clinical features. To document the clinical and epidemiologic characteristics that distinguish these 2 rickettsial diseases, during 2004-2015 we recruited 31 JSF patients, 188 ST patients, and 97 nonrickettsial disease patients from the Southern Boso Peninsula of Japan. JSF occurred during April-October and ST during November-December. Patients with JSF and ST were significantly older and more likely to reside in wooded areas than were patients with nonrickettsial diseases. Spatial analyses revealed that JSF and ST clusters rarely overlapped. Clinical findings more frequently observed in JSF than in ST patients were purpura, palmar/plantar rash, hyponatremia, organ damage, and delayed defervescence after treatment. Although their clinical features are similar, JSF and ST differ in seasonality, geographic distribution, physical signs, and severity. Because a considerable percentage of patients did not notice rash and eschar, many rickettsial diseases might be underdiagnosed in Japan.
\end{abstract}

$\mathrm{T}$ wo rickettsial diseases are endemic to Japan, scrub typhus (ST) and Japanese spotted fever (JSF). ST, which is also called tsutsugamushi disease (1), was first reported in central Japan in 1878 (2). ST is caused by the miteborne pathogen Orientia tsutsugamushi. According to the national surveillance data of notifiable diseases in Japan, during 2004-2015, the number of reported ST cases was nearly constant; each year on average, 396 ST cases and 2 deaths (case-fatality rate $0.5 \%$ ) were reported (3). ST was originally believed to be confined to the Asia-Pacific region; however, ST has recently been reported in Kenya (4) and southern Chile (5). In 1984, JSF was identified in western Japan (6). JSF is caused by the tickborne pathogen Rickettsia japonica (7). Except for a case reported in South

Author affiliations: Nagasaki University, Nagasaki, Japan (E. Sando, M. Suzuki, S. Katoh, K. Ariyoshi); Kameda Medical Center, Kamogawa, Japan (E. Sando, M. Yaegashi); Mahara Institute of Medical Acarology, Anan, Japan (H. Fujita); Chiba Prefectural Institute of Public Health, Chiba, Japan (M. Taira)

DOI: https://doi.org/10.3201/eid2409.171436
Korea (8), JSF is endemic nearly exclusively to the central and western portions of Japan (3). Recently, the number of reported JSF cases in this region increased, from 66 in 2004 to 215 in 2015, and the case-fatality rate increased from $1.5 \%$ to $2.3 \%$ (3); thus, JSF is a public health concern. Although JSF and ST have been reported in several prefectures in Japan, the areas of endemicity rarely overlap at the district level (3). One of the rare districts to which both JSF and ST are endemic is the southern Boso Peninsula, Chiba Prefecture, in central Japan.

The typical signs and symptoms of JSF and ST are similar (e.g., fever, rash, and eschar), although in patients with ST, the frequency of rash varies from $14 \%$ to $93 \%$ and of eschar from $8 \%$ to $93 \%$ (9-13). For a few patients with JSF and ST, severe conditions develop (14-17). However, clinical information regarding JSF has been limited by lack of an appropriate case definition, lack of in-depth information, and studies involving small sample sizes $(14,16)$. The clinical features observed in patients with JSF and ST are not comparable across studies because of the different enrollment criteria and nonstandardized case definitions. To clarify the clinical and epidemiologic characteristics of JSF and ST patients by using stringent laboratory confirmation methods and to identify the factors that distinguish the 2 diseases, we conducted a multicenter study in the southern Boso Peninsula in central Japan, an area of high JSF and ST endemicity. The study was approved by the institutional review boards of the Kameda Medical Center and the Awa Regional Medical Center.

\section{Methods}

\section{Study Design and Setting}

The southern Boso Peninsula is a predominantly rural mountainous region with a long coastline facing the $\mathrm{Pa}-$ cific Ocean and Tokyo Bay. According to the census, the total population in 2015 was 350,000 and $35.4 \%$ of the residents were $\geq 65$ years of age. We conducted prospective and retrospective case series reviews at 3 medical facilities: Kameda Medical Center (865 acute beds), Awa Regional 
Medical Center (149 beds), and Kameda Family ClinicTateyama (no beds).

\section{Study Period and Entry Criteria}

We prospectively enrolled patients from January 1, 2011, through December 31, 2015. We collected clinical, epidemiologic, and laboratory data from the patients who visited the study hospitals and exhibited signs and symptoms compatible with rickettsial disease. The patients were suspected to have rickettsial disease if they had any of the following clinical signs or symptoms without other apparent causes: fever, rash, eschar, respiratory symptoms, altered mental status, lymphadenopathy, neurologic abnormalities, systematic pain, chills/rigors, headache, or malaise. Using the same enrollment criteria, we also retrospectively collected data from patients who visited the study hospitals from January 1, 2004, through December 31, 2010, and who were not included in the prospective data collection. We used a standardized format to extract clinical and epidemiologic information from electronic medical records.

\section{Laboratory Methods}

All blood samples were sent to a commercial laboratory (SRL, Inc., Tokyo) for an indirect immunofluorescence assay (IFA) to identify the $O$. tsutsugamushi serotypes Kato, Karp, and Gilliam; the antigens were provided by Denka Seiken Co., Ltd. If JSF was suspected, the samples were sent to the Chiba Prefectural Institute of Public Health for IFA to identify the O. tsutsugamushi serotypes Kato, Karp, Gilliam, Irie/Kawasaki, Hirano/Kuroki, and $R$. japonica (YH strain). The blood samples collected during 2009 and 2010 were also sent to the Ohara Research Laboratory (Fukushima City, Japan), and samples collected during 2014 were sent to the Mahara Institute of Medical Acarology (Anan, Japan) for an indirect immunoperoxidase assay to identify $6 O$. tsutsugamushi serotypes (the previously mentioned 5 serotypes plus the serotype Shimokoshi), $R$. japonica (Aoki strain), and R. typhi (18). The type-specific whole rickettsial particles were used as antigens in the IFA and immunoperoxidase assays. Serum samples were diluted from 1:40 to 1:40,960 for immunoperoxidase assays and from 1:10 (or 20) to 1:10,240 for IFA. The titer was expressed as the reciprocal of the highest dilution. Nested PCR assays were performed to identify the $56-\mathrm{kDa}$ antigen of $O$. tsutsugamushi and the 17-kDa genus-common antigen of $R$. japonica from eschars at the Chiba Prefectural Institute of Public Health (Chiba, Japan) or Kameda Medical Center (Kamogawa, Japan) $(19,20)$.

\section{Case Definitions and Data Collection}

A patient's rickettsial status was defined as confirmed if the PCR result from the eschar was positive for any rickettsiae or if $\mathrm{a} \geq 4$-fold increase in the IgM or IgG titer of IFA or immunoperoxidase assay was observed in paired serum samples (i.e., acute and convalescent phases). A patient's status that did not fulfill the criteria for confirmed was defined as probable if the IgM titer of IFA or immunoperoxidase assay was $\geq 80$ for JSF or ST. A patient's status was defined as possible if the clinical course was compatible with that of JSF or ST but the laboratory test results did not fulfill the criteria for either confirmed or probable. A patient was defined as having a nonrickettsial disease if a diagnosis of an infectious or noninfectious disease other than a rickettsial disease was confirmed. We excluded from analysis those patients who were classified as having possible cases or a diagnosis of murine typhus or concurrent JSF and ST infection.

Traditionally, in Japan, fever, rash, and eschar have been considered the triad of JSF and ST. We classified the triad into 3 categories: 1) "chief complaint" if any of the signs were the reason for the visit; 2) "upon history collection" if patients noticed the signs but had not complained until the physician asked; and 3) "physical exam" if the signs were objectively identified at the initial physical examination.

\section{Statistical Analyses}

The clinical and epidemiologic characteristics of the patients were summarized and compared according to the 3 categories (i.e., JSF, ST, and nonrickettsial diseases). We used $\chi^{2}$ or Fisher exact tests to compare characteristics of the patients by disease category. We computed odds ratios (ORs) with $95 \%$ CIs by using logistic regression models.

The patients' home addresses were geocoded and plotted on maps by using ArcGIS version 10.4.1 (Esri, Redlands, CA, USA). We calculated the population density and land use percentage within a radius of $500 \mathrm{~m}$ based on the census data and compared the 3 categories by using the Mann-Whitney U test. The Kulldorff scan statistics tool (SaTScan version 9.4.4) was used to identify the geographic clusters of JSF and ST (21). All tests were 2 -tailed, and $p<0.05$ was considered statistically significant. All clinical data analyses were performed by using STATA version 13.0 (StataCorp LLC, College Station, Texas, USA).

\section{Results}

\section{Laboratory Confirmation}

A total of 661 patients were enrolled in the study: 303 by prospective and 358 by retrospective data collection. Overall, $42 \%$ of the patients were female, and the mean age was 60 years. Of the 50 patients whose eschars were tested by nested PCR, 8 were positive for $R$. japonica DNA and 29 were positive for $O$. tsutsugamushi DNA. The O. tsutsugamushi serotypes were identified in 22 patients; 16 were the Irie/Kawasaki type and 6 were the 
Hirano/Kuroki type. All patients were tested by an IFA at least 1 time, and paired blood samples were available for $304(46 \%)$ patients. The median time from acute-phase sample collection to convalescent-phase sample collection was 14 days (interquartile range 11-17 days). Of the 304 patients, JSF was confirmed for 33 and ST was confirmed for 155 . Of the 357 patients whose convalescentphase samples were unavailable, none had probable JSF and 35 had probable ST. Three patients who did not fulfill the serologic criteria for having a rickettsial disease but whose eschar was positive for $O$. tsutsugamushi DNA were confirmed as having ST. Two patients fulfilled the criteria for having both JSF and ST, and 1 patient was confirmed to have murine typhus. Overall, our analysis included 31 patients with JSF, 188 patients with ST, and 97 patients with nonrickettsial diseases (Figure 1). The final diagnoses of the nonrickettsial diseases are shown in online Technical Appendix Table 1 (https://wwwnc.cdc. gov/EID/article/24/9/17-1436-Techapp1.pdf).

\section{Seasonal and Geographic Distributions}

The seasonal distributions of JSF, ST, and nonrickettsial diseases are shown in Figure 2. All patients with JSF visited a medical facility during April-October; the numbers peaked slightly in July. Most (91\%) patients with ST visited a medical facility in either November or December. No seasonal trend was observed for nonrickettsial diseases.

The geographic distributions are shown in Figure 3. We identified 1 JSF cluster $(\mathrm{p}<0.001)$ and 2 ST clusters $(p=0.013$ and $p=0.041)$, and these clusters rarely overlapped. Patients with JSF and ST resided in less populated areas (population densities within a 500-m radius were $255 / \mathrm{km}^{2}$ and $295 / \mathrm{km}^{2}$, respectively) than patients with nonrickettsial diseases $\left(904 / \mathrm{km}^{2} ; \mathrm{p}<0.001\right)$. Patients with JSF and ST more frequently resided in wooded areas (proportions in forested area within a $500-\mathrm{m}$ radius were $51 \%$ and $43 \%$, respectively) than patients with nonrickettsial diseases $(17 \% ; \mathrm{p}<0.001)$.

\section{Demographic and Clinical Features}

The baseline characteristics of the patients are summarized in Table 1. The proportion of female patients did not differ among the 3 groups. Patients with JSF and ST were older than patients with nonrickettsial diseases; among patients in the oldest age group, JSF occurred more frequently than ST. Patients with JSF and ST were more frequently exposed to the natural outdoor environment than were patients with nonrickettsial diseases.

Clinical characteristics of the patients are summarized in Table 2. The triad (i.e., fever, rash, and eschar) was commonly observed by physicians but not necessarily noticed by the patients. Fever was a primary sign; however, at the initial physical examination, body temperature was high in only $74 \%$ of patients with JSF and $73 \%$ with ST. Among patients who did not have a high body temperature at their initial physical examination, fever developed during hospitalization for $5(71 \%)$ of 7 with JSF and $9(38 \%)$ of 24 with ST. Although most patients had a rash, only $60 \%$ of patients with JSF and $44 \%$ with ST had noticed their rash. Moreover, only $45 \%$ of patients with JSF and $28 \%$ of patients with ST reported their rash. Most patients did not notice the presence of eschar.

During physical examination, patients with JSF had hypotension more frequently than patients with ST (OR 5.1, 95\% CI 1.9-13.8), but no significant difference was observed in the frequency of tachycardia and tachypnea. Considerably higher proportions of patients with JSF and ST than with nonrickettsial diseases had a rash and eschar; the mean \pm SD size of the eschar was smaller in patients with JSF $(5.8 \pm 2.1 \mathrm{~mm})$ than in patients with ST $(9.7 \pm 5.6$ $\mathrm{mm} ; \mathrm{p}=0.024)$. Purpura, palmar/plantar rash, and lung involvement were more frequently observed in patients with JSF than in those with ST. Prevalence of lymphadenopathy did not differ among the groups.

Patients with JSF and ST were less likely than patients with nonrickettsial diseases to have leukocytosis and anemia but more likely to have elevated aspartate aminotransferase and lactate dehydrogenase levels, hyponatremia,

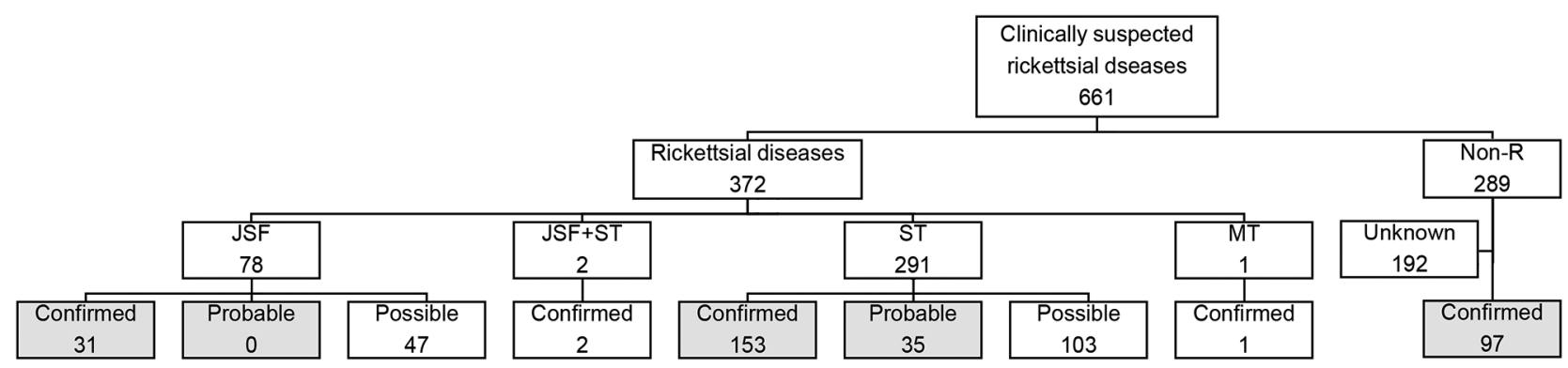

Figure 1. Numbers of patients with rickettsial or nonrickettsial diseases, Japan, 2004-2015. Of 43 patients tested by immunofluorescence and immunoperoxidase assays, 4 fulfilled the criteria for having confirmed JSF, 7 for confirmed ST, and 7 for probable ST. Gray shading indicates the cases included in the main analysis. JSF, Japanese spotted fever; MT, murine typhus; non-R, nonrickettsial diseases; ST, scrub typhus. 


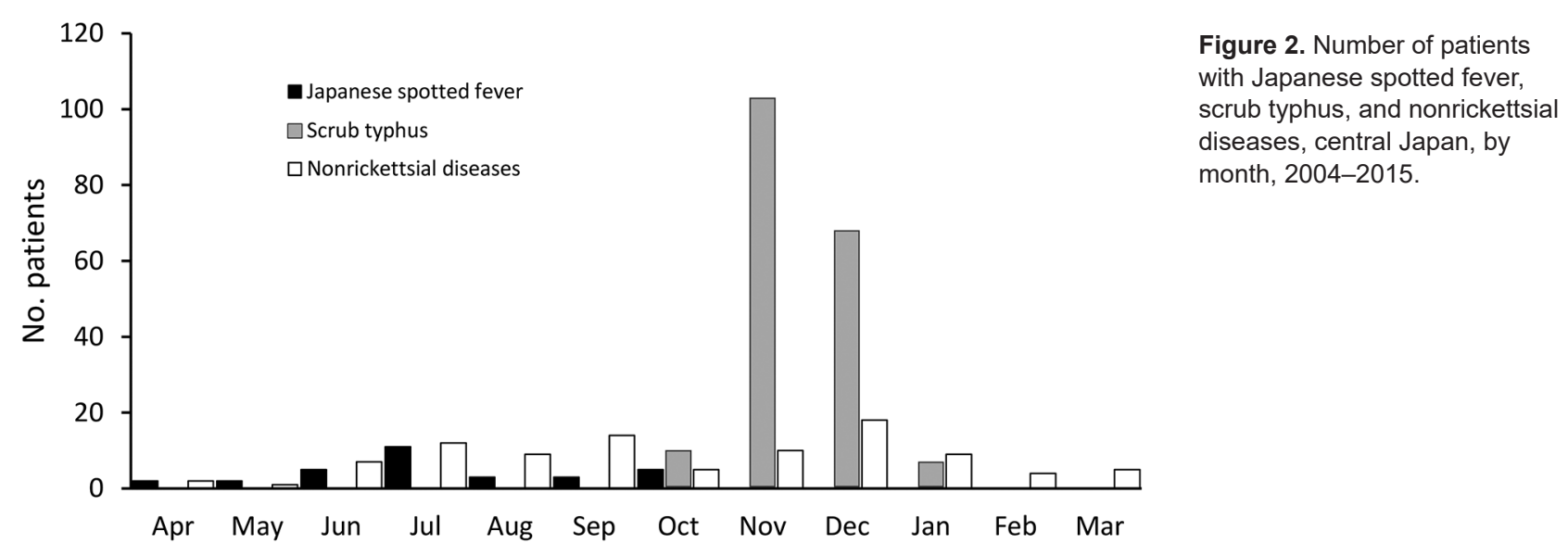

and urine occult blood (Table 3). Patients with JSF were more likely than patients with ST to have low platelet counts; elevated bilirubin, creatinine kinase, blood urea nitrogen, and creatinine levels; hyponatremia; and high Creactive protein.

Patients with JSF required hospitalization more frequently than did patients with ST; these associations did not change after we adjusted for age. Patients with JSF tended to visit a medical facility earlier than did patients in the other groups. JSF and ST were successfully treated in patients who received tetracycline; a 51-year-old patient receiving psychiatric care died of ST, but no patient died of JSF. The time to defervescence after treatment was longer for patients with JSF than for patients with ST.

\section{Discussion}

By using standardized laboratory definitions for diagnosis, we determined that the clinical and epidemiologic characteristics of JSF and ST in Japan differed by seasonality, geographic distribution, physical signs, and severity. JSF and ST showed distinct seasonal patterns. JSF occurred during April-October and peaked slightly in July, whereas most ST occurred during November-December. JSF and ST were distributed in less populated and more wooded areas, although their geographic clusters rarely overlapped. Patients with JSF were more likely than patients with ST to have purpura, palmar/plantar rash, and organ damage and to be hospitalized.

The different seasonal distribution of JSF and ST observed in our study can be explained by the ecology of the vectors $(3,22)$ as follows: 1) Haemaphysalis flava and $H$. longicornis ticks, which transmit $R$. japonica, are active from spring until autumn in Chiba (23); 2) Leptotorombidium scutellare mites, which transmit the Irie/Kawasaki (and Hirano/Kuroki) serotypes of $O$. tsutsugamushi, are active in autumn and early winter (24) and unable to survive the winter; and 3) L. pallidum mites, which transmit the Karp and Gilliam serotypes of O. tsutsugamushi, are active from October through May (24). The difference in geographic distributions of JSF and ST may also be explained by the different distribution of the reservoirs in our study settings. Sika deer are wild hosts of ticks, and their distribution overlaps with that of ticks (25). The cluster of JSF identified in our study overlapped with the distribution of sika deer and Reeves's muntjacs, which are related to sika deer $(26,27)$. In contrast, the field rat, which is the primary host of the Leptotrombidium mite, is spreading throughout this area, which may explain the wide distribution of ST. Although our data are limited, similar patterns (i.e., the clustering of JSF and relatively wide distribution of ST) were also observed in other prefectures $(28,29)$. Further studies are needed to establish the temporal and geographic associations among the vectors, reservoirs, and rickettsial pathogens.

Although the clinical features of patients in this study with JSF and ST were similar, some clinical findings were characteristic of JSF. Patients with JSF more frequently had rashes on the palms/soles, purpura, and small eschars. Moreover, the following severe conditions occurred more frequently among patients with JSF than among those with ST: hypotension, low platelet counts, and increased creatinine levels. Rickettsiae invade and proliferate within vascular endothelial cells and cause a vasculitis-like systemic disease (30). In a study by Tai et al., cytokine and chemokine levels were higher in patients with JSF than in patients with ST, but no significant association was observed between cytokine levels and the clinical severity of disease (17). Although previous human and animal model studies have revealed the pathogenic mechanisms of severe rickettsial infections (31-32), the mechanisms of severe JSF remain not fully understood. Of note, the clinical severity of ST may differ according to the Orientia serotype. According to a systematic review, the mortality rate from ST substantially varied according to patients' age, co-occurring conditions, and regional Rickettsia strains (33). Our findings of ST in regions where Irie/Kawasaki type and Hirano/ 

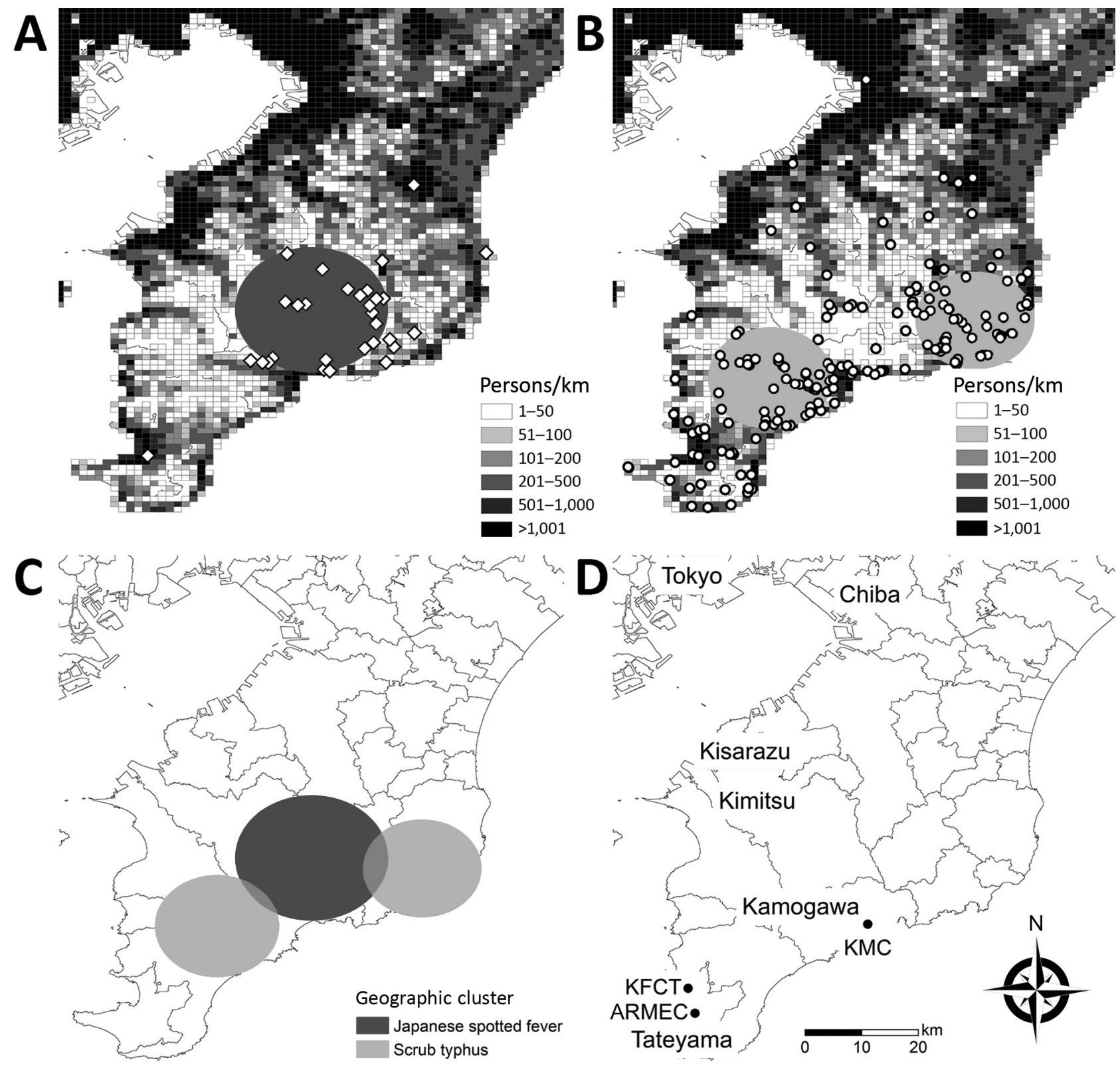

Figure 3. Geographic distribution and clusters of JSF and ST, Japan, 2004-2015. A) JSF; B) ST; C) geographic clusters of JSF and ST; D) locations of study facilities. White diamonds (JSF) and circles (ST) represent the locations of each patient's address. Shaded circles (black, JSF; gray, ST) represent statistically significant spatial clusters $(p<0.05)$. The geographic distribution of the patients with nonrickettsial diseases, which were used for the cluster analysis as the reference, is shown in the Technical Appendix Figure (https:// wwwnc.cdc.gov/EID/article/24/9/17-1436-Techapp1.pdf). ARMEC, Awa Regional Medical Center; JSF, Japanese spotted fever; KFCT, Kameda Family Clinic Tateyama; KMC, Kameda Medical Center; ST, scrub typhus.

Kuroki type are endemic may not be directly applicable to other settings in which other serotypes are endemic, such as Akita and Niigata in northern Japan.

Fever has been considered one of the typical signs of JSF and ST. Most patients in our study had a high body temperature during the clinical course of their illness; however, fever was not apparent at the time of initial physical examination for $26 \%$ of patients with JSF and $27 \%$ of patients with ST. Although rash and eschar were commonly observed by the physicians, more than half of the patients did not notice these signs. Consequently, 33\% of the patients with JSF and $34 \%$ of the patients with ST received incorrect diagnoses during their first medical visit. Furthermore, fewer clinicians were aware of JSF than of ST (34). These findings indicate that a substantial number of rickettsial diseases may be underdiagnosed in Japan. 
Table 1. Baseline characteristics of patients with JSF, ST, and nonrickettsial diseases, central Japan, 2004-2015*

\begin{tabular}{|c|c|c|c|c|c|c|c|c|c|}
\hline \multirow[b]{2}{*}{ Characteristic } & \multirow{2}{*}{$\begin{array}{c}\text { JSF, } \\
\text { no. }(\%) \\
\text { n }=31\end{array}$} & \multirow{2}{*}{$\begin{array}{c}\mathrm{ST}, \\
\text { no. }(\%), \\
\mathrm{n}=188\end{array}$} & \multirow{2}{*}{$\begin{array}{c}\text { Non-R, } \\
\text { no. }(\%) \\
n=97\end{array}$} & \multicolumn{2}{|c|}{ JSF vs. non-R† } & \multicolumn{2}{|c|}{ ST vs. non-R† } & \multicolumn{2}{|c|}{ JSF vs. ST } \\
\hline & & & & OR $(95 \% \mathrm{Cl})$ & $p$ value & OR (95\% Cl) & $p$ value & OR (95\% Cl) & $p$ value \\
\hline $\begin{array}{l}\text { Female sex } \\
\text { Age, y, mean (SD) }\end{array}$ & $\begin{array}{l}16(52) \\
73(10)\end{array}$ & $\begin{array}{l}85(45) \\
65(15) \\
\end{array}$ & $\begin{array}{l}35(36) \\
57(20)\end{array}$ & $1.9(0.8-4.3)$ & 0.127 & $1.5(0.9-2.4)$ & 0.14 & $1.3(0.6-2.8)$ & 0.509 \\
\hline Age group, y & & & & & & & & & \\
\hline$\leq 54$ & $1(3)$ & $29(15)$ & $43(44)$ & Reference & & Reference & & Reference & \\
\hline$\overline{55-64}$ & $7(23)$ & $48(26)$ & $14(14)$ & $21.5(2.4-190.3)$ & 0.006 & $5.1(2.4-10.9)$ & $<0.001$ & $4.2(0.5-36.1)$ & 0.188 \\
\hline $65-74$ & 7 (23) & $56(30)$ & $13(13)$ & $23.2(2.6-205.9)$ & 0.005 & $6.4(3.0-13.7)$ & $<0.001$ & $3.6(0.4-30.9)$ & 0.239 \\
\hline$>75$ & $16(52)$ & $55(29)$ & $27(28)$ & $25.5(3.2-203.3)$ & 0.002 & $3.0(1.6-5.8)^{\prime}$ & 0.001 & $8.4(1.1-66.8)$ & 0.043 \\
\hline No exposure & $1(3)$ & $18(12)$ & $32(46)$ & Reference & & Reference & & Reference & \\
\hline $\begin{array}{l}\text { Living in/ } \\
\text { stepped into } \\
\text { mountainous } \\
\text { areas }\end{array}$ & $12(40)$ & $58(38)$ & $16(23)$ & $24.0(2.9-201.2)$ & 0.003 & $6.4(2.9-14.3)$ & $<0.001$ & $3.7(0.5-30.6)$ & 0.162 \\
\hline $\begin{array}{l}\text { Stepped into a } \\
\text { bush }\end{array}$ & $1(3)$ & $12(8)$ & $3(4)$ & $10.7(0.5-217.2)$ & 0.124 & $7.1(1.8-28.6)$ & 0.006 & $1.5(0.1-26.4)$ & 0.162 \\
\hline Farming & $16(53)$ & $65(42)$ & $14(20)$ & $36.6(4.4-303.4)$ & 0.001 & $8.3(3.6-18.7)$ & $<0.001$ & $4.4(0.5-35.7)$ & 0.162 \\
\hline
\end{tabular}

*JSF, Japanese spotted fever; non-R, nonrickettsial diseases; OR, odds ratio; ST, scrub typhus.

†Non-R reference.

¥ST reference.

Because of the difficulties associated with locating patients to collect blood samples during the convalescent phase of illness, previous studies have relied on laboratory confirmation that uses acute-phase samples with variable cutoff IgM titers without considering local endemicity, which may have resulted in misclassification (35). In this study, we used the IFA or immunoperoxidase IgM titer of $\geq 80$ as a cutoff for the diagnosis of

\begin{tabular}{|c|c|c|c|c|c|c|c|c|c|}
\hline \multirow[b]{2}{*}{ Characteristic } & \multirow{2}{*}{$\begin{array}{c}\text { JSF, } \\
\text { no. (\%), } \\
n=31\end{array}$} & \multirow{2}{*}{$\begin{array}{c}\mathrm{ST} \\
\text { no. }(\%) \\
\mathrm{n}=188\end{array}$} & \multirow{2}{*}{$\begin{array}{c}\text { Non-R, } \\
\text { no. }(\%), \\
\text { n }=97\end{array}$} & \multicolumn{2}{|c|}{ JSF vs. non-R† } & \multicolumn{2}{|c|}{ ST vs. non-R† } & \multicolumn{2}{|c|}{ JSF vs. ST } \\
\hline & & & & OR $(95 \% \mathrm{Cl})$ & $p$ value & OR $(95 \% \mathrm{Cl})$ & $p$ value & OR $(95 \% \mathrm{CI})$ & $p$ value \\
\hline \multicolumn{10}{|l|}{ Chief complaint } \\
\hline Fever & $26(84)$ & $135(72)$ & $78(80)$ & $1.3(0.4-3.7)$ & 0.668 & $0.6(0.3-1.1)$ & 0.115 & $2.0(0.7-5.6)$ & 0.165 \\
\hline Rash & $14(45)$ & $52(28)$ & 17 (18) & $3.9(1.6-9.3)$ & 0.003 & $1.8(1.0-3.3)$ & 0.06 & $2.2(1.0-4.7)$ & 0.053 \\
\hline Eschar & $0(0)$ & $5(3)$ & $1(1)$ & Not applicable & $1.000 \S$ & $2.6(0.3-22.8)$ & 0.382 & Not applicable & $1.000 \S$ \\
\hline Headache & $1(3)$ & 29 (15) & $5(5)$ & $0.6(0.1-5.5)$ & 0.661 & $3.4(1.3-9.0)$ & 0.016 & $0.2(0-1.4)$ & 0.101 \\
\hline Fatigue & $3(10)$ & 35 (19) & $6(6)$ & $1.6(0.4-6.9)$ & 0.511 & $3.5(1.4-8.6)$ & 0.007 & $0.5(0.1-1.6)$ & 0.233 \\
\hline \multicolumn{10}{|l|}{ At history collection } \\
\hline Fever & $27(87)$ & $148(82)$ & $81(84)$ & $1.3(0.4-4.1)$ & 0.712 & $0.8(0.4-1.6)$ & 0.586 & $1.5(0.5-4.6)$ & 0.473 \\
\hline Rash & $18(60)$ & $74(44)$ & $24(26)$ & $4.3(1.8-10.1)$ & 0.001 & $2.2(1.3-3.8)$ & 0.099 & $2.0(0.9-4.3)$ & 0.664 \\
\hline Eschar & $1(4)$ & $20(12)$ & $5(6)$ & $0.6(0.1-5.5)$ & 0.664 & $2.1(0.8-5.9)$ & 0.141 & $0.3(0-2.2)$ & 0.232 \\
\hline Headache & $4(25)$ & $75(56)$ & $27(59)$ & $0.2(0.1-0.8)$ & 0.026 & $0.9(0.5-1.8)$ & 0.748 & $0.3(0.1-0.9)$ & 0.026 \\
\hline Fatigue & $17(94)$ & $97(84)$ & $32(94)$ & $1.1(0.1-12.6)$ & 0.962 & $0.3(0.1-1.4)$ & 0.138 & $3.3(0.4-26.5)$ & 0.256 \\
\hline \multicolumn{10}{|c|}{ Physical examination findings } \\
\hline $\mathrm{BT}>37.5^{\circ} \mathrm{C}$ & $23(74)$ & $132(73)$ & $53(59)$ & $2.0(0.8-5.0)$ & 0.132 & $1.9(1.1-3.2)$ & 0.02 & $1.1(0$. & 0.883 \\
\hline Hypotension & $8(26)$ & $12(6)$ & $5(5)$ & $6.4(1.9-21.4)$ & 0.003 & $1.3(0.4-3.7)$ & 0.679 & $5.1(1.9-13.8)$ & 0.001 \\
\hline $\begin{array}{l}\text { Heart rate } \\
>120 \mathrm{bpm}\end{array}$ & $2(7)$ & $13(8)$ & $6(7)$ & $0.9(0.2-4.9)$ & 0.942 & $1.2(0.4-3.2)$ & 0.777 & $0.8(0.2-3.8)$ & 0.793 \\
\hline $\begin{array}{l}\text { Respiratory rate } \\
>20 / \text { min }\end{array}$ & $13(54)$ & $40(39)$ & $23(45)$ & $1.4(0.5-3.8)$ & 0.464 & $0.8(0.4-1.5)$ & 0.457 & $1.9(0.8-4.6)$ & 0.174 \\
\hline $\begin{array}{l}\text { Altered mental } \\
\text { status }\end{array}$ & $5(16)$ & $14(7)$ & $15(15)$ & $1.1(0.3-3.2)$ & 0.929 & $0.4(0.2-1.0)$ & 0.038 & $2.4(0.8-7.2)$ & 0.121 \\
\hline Rash & $30(100)$ & $181(96)$ & $52(57)$ & Not applicable & $<0.001 \S$ & $19.4(8.2-45.9)$ & $<0.001$ & Not applicable & $0.597 \S$ \\
\hline Localized & 0 & $3(2)$ & $6(12)$ & Not applicable & $0.079 \S$ & $0.1(0-0.5)$ & 0.004 & Not applicable & $1.000 \S$ \\
\hline Purpura & $11(44)$ & $4(2)$ & $7(8)$ & $8.9(2.9-26.8)$ & $<0.001$ & $0.2(0.1-0.9)$ & 0.028 & $\begin{array}{c}36.1 \\
(10.1-128.3)\end{array}$ & $<0.001$ \\
\hline Palms/soles & $21(84)$ & $13(7)$ & $4(5)$ & $\begin{array}{c}101.1 \\
(23.3-438.4)\end{array}$ & 0.001 & $1.4(0.5-4.6)$ & 0.537 & $\begin{array}{c}70.3 \\
(21.0-235.3)\end{array}$ & $<0.001$ \\
\hline Eschar & 24 (89) & $163(87)$ & $18(22)$ & $\begin{array}{c}28.0 \\
(7.6-103.7)\end{array}$ & $<0.001$ & $\begin{array}{c}23.8 \\
(12.1-46.8)\end{array}$ & $<0.001$ & $1.2(0.3-4.2)$ & 0.801 \\
\hline un & & 21 (11) & $9(9)$ & $3.4(1.2-9.8)$ & 0.023 & $1.2(0.5-2.8)$ & 0.6 & $2.8(1.1-7.0)$ & 0.0 \\
\hline
\end{tabular}

${ }^{*} \mathrm{BT}$, body temperature; involve, involvement; JSF, Japanese spotted fever; non-R, nonrickettsial diseases; OR, odds ratio; ST, scrub typhus.

$\dagger$ Non- $R=$ reference.

†ST = reference.

$\S$ Fisher exact tests.

TSystolic blood pressure $<90 \mathrm{~mm} \mathrm{Hg}$ or vasopressor usage.

\#Lung rales with pulmonary infiltrative shadow. 
Japanese Spotted Fever and Scrub Typhus

Table 3. Laboratory and treatment data for patients with JSF, ST, and nonrickettsial diseases, central Japan, 2004-2015*

\begin{tabular}{|c|c|c|c|c|c|c|c|c|c|}
\hline \multirow[b]{2}{*}{ Characteristic } & \multirow{2}{*}{$\begin{array}{c}\text { JSF, } \\
\text { no. (\%), } \\
\text { n = 31 }\end{array}$} & \multirow{2}{*}{$\begin{array}{c}\mathrm{ST}, \\
\text { no. }(\%), \\
\mathrm{n}=188\end{array}$} & \multirow{2}{*}{$\begin{array}{c}\text { Non-R, } \\
\text { no. }(\%), \\
\mathrm{n}=97\end{array}$} & \multicolumn{2}{|c|}{ JSF vs. non-R† } & \multicolumn{2}{|c|}{ ST vs. non-R† } & \multicolumn{2}{|c|}{ JSF vs. ST } \\
\hline & & & & OR $(95 \% \mathrm{Cl})$ & $p$ value & OR $(95 \% \mathrm{Cl})$ & $p$ value & OR $(95 \% \mathrm{Cl})$ & $p$ value \\
\hline \multicolumn{10}{|l|}{ Laboratory data } \\
\hline $\begin{array}{l}\text { Leukocytes } \\
>9,800 / \mu \mathrm{L}\end{array}$ & $5(16)$ & $23(12)$ & $42(45)$ & $0.2(0.1-0.7)$ & 0.006 & $0.2(0.1-0.3)$ & $<0.001$ & $1.4(0.5-3.9)$ & 0.556 \\
\hline $\begin{array}{l}\mathrm{Hb}<11 \mathrm{~g} / \mathrm{dL}(\mathrm{F}) \\
\text { or }<13.5 \mathrm{~g} / \mathrm{dL} \\
(\mathrm{M})\end{array}$ & $5(16)$ & $29(16)$ & $46(49)$ & $0.2(0.1-0.6)$ & 0.002 & $0.2(0.1-0.3)$ & $<0.001$ & $1.0(0.4-2.9)$ & 0.939 \\
\hline $\begin{array}{l}\text { Platelets } \\
<130,000 / \mu \mathrm{L}\end{array}$ & $22(71)$ & $59(32)$ & $28(30)$ & $5.7(2.3-13.9)$ & $<0.001$ & $1.1(0.6-1.8)$ & 0.806 & $5.3(2.3-12.2)$ & $<0.001$ \\
\hline $\begin{array}{l}\text { Albumin } \\
<3.4 \mathrm{~g} / \mathrm{dL}\end{array}$ & $14(61)$ & 37 (29) & $31(55)$ & $1.3(0.5-3.4)$ & 0.653 & $0.3(0.2-0.6)$ & 0.001 & $3.8(1.5-9.6)$ & 0.004 \\
\hline IU/L & $29(94)$ & $154(83)$ & $46(50)$ & $\begin{array}{c}14.5 \\
(3.3-64.3)\end{array}$ & $<0.001$ & $4.8(2.8-8.4)$ & $<0.001$ & $3.0(0.7-13.3)$ & 0.145 \\
\hline$A L T$ & $16(52)$ & $00(54)$ & $42(46)$ & $1.3(0.6-2.9)$ & 0.566 & $1.4(0.8-2.3)$ & 0.204 & $0.9(0.4-2.0)$ & 0.824 \\
\hline $\mathrm{LDH}>229 \mathrm{IU} / \mathrm{L}$ & $30(97)$ & 179 (97) & $70(78)$ & $8.6(1.1-66.8)$ & 0.040 & $8.5(3.3-22.1)$ & $<0.001$ & $1.0(0.1-8.7)$ & 0.996 \\
\hline $\begin{array}{l}\text { Total bilirubin } \\
>1.0 \mathrm{mg} / \mathrm{dL}\end{array}$ & $9(29)$ & $13(7)$ & 15 (17) & $2.0(0.8-5.1)$ & 0.166 & $0.4(0.2-0.8)$ & 0.016 & $5.2(2.0-13.6)$ & 0.001 \\
\hline $\begin{array}{l}\text { Direct bilirubin } \\
>0.4 \mathrm{mg} / \mathrm{dL}\end{array}$ & $4(22)$ & $7(5)$ & $16(28)$ & $0.8(0.2-2.6)$ & 0.652 & $0.1(0.1-0.4)$ & $<0.001$ & $5.2(1.3-19.9)$ & 0.017 \\
\hline $\begin{array}{l}\text { Creatine kinase } \\
>150 \mathrm{IU} / \mathrm{L}\end{array}$ & $19(66)$ & $46(29)$ & $21(28)$ & $4.9(2.0-12.2)$ & 0.001 & $1.2(0.6-1.9)$ & 0.861 & $4.6(2.0-10.7)$ & $<0.001$ \\
\hline $2 \mathrm{mg} / \mathrm{dL}$ & $15(48)$ & $35(19)$ & $20(22)$ & $3.4(1.4-8.0)$ & 0.006 & $0.8(0.5-1.6)$ & 0.58 & $4.0(1.8-8.9)$ & 0.001 \\
\hline $\begin{array}{l}\text { Creatinine } \\
>1.2 \mathrm{mg} / \mathrm{dL}\end{array}$ & $11(35)$ & $22(12)$ & 7 (8) & $6.7(2.3-19.4)$ & $<0.001$ & $1.6(0.7-4.0)$ & 0.277 & $4.1(1.7-9.6)$ & 0.001 \\
\hline $\begin{array}{l}\text { Sodium } \\
<135 \mathrm{mEq} / \mathrm{L}\end{array}$ & $24(77)$ & $71(39)$ & $16(17)$ & $\begin{array}{c}16.3 \\
(6.0-44.3)\end{array}$ & $<0.001$ & $3.0(1.6-5.6)$ & $<0.001$ & $5.4(2.2-13.2)$ & $<0.001$ \\
\hline $\begin{array}{l}\text { Chloride } \\
<98 \mathrm{mEq} / \mathrm{L}\end{array}$ & $17(55)$ & $37(22)$ & $15(16)$ & $6.2(2.5-15.3)$ & $<0.001$ & $1.4(0.7-2.7)$ & 0.302 & $4.4(2.0-9.7)$ & $<0.001$ \\
\hline C & $16(52)$ & $32(18)$ & 40) & $1.6(0.7-3$. & 0.266 & $-0.6)$ & $<0.001$ & $5.0(2.2-11.1)$ & $<0.001$ \\
\hline & $27(87)$ & $6(75)$ & (62) & $4.2(1.3-13$ & 0.018 & $-3.5)$ & & $2.3(0.7-6.9)$ & 0.148 \\
\hline Urin & $29(94)$ & $2(79)$ & $1(56)$ & $.2(2.4-51$ & 0.002 & 2.9 & 0.002 & $3.9(0.9-17.3)$ & 0.071 \\
\hline \multicolumn{10}{|c|}{ Treatment and prognosis } \\
\hline $\begin{array}{l}\text { Duration of } \\
\text { illness } \S<5 d\end{array}$ & $16(59)$ & $74(39)$ & $24(27)$ & $4.0(1.6-9.8)$ & 0.002 & $1.8(1.0-3.1)$ & 0.039 & $2.2(1.0-5.1)$ & 0.054 \\
\hline $\begin{array}{l}\text { Treatment: } \\
\text { MINO/DOXY }\end{array}$ & $31(100)$ & $180(99)$ & $42(91)$ & Not applicable & $0.144 \rrbracket$ & $\begin{array}{c}17.1(1.9- \\
157.4)\end{array}$ & 0.012 & Not applicable & $1.000 \rrbracket$ \\
\hline $\begin{array}{l}\text { Delayed } \\
\text { defervescence\# }\end{array}$ & $11(37)$ & $17(13)$ & $30(67)$ & $0.3(0.1-0.8)$ & 0.012 & $0.1(0-0.2)$ & $<0.001$ & $3.8(1.5-9.3)$ & 0.004 \\
\hline Hospitalization & $28(90)$ & $104(55)$ & $80(82)$ & $2.0(0.5-7.3)$ & 0.302 & $1-0.5)$ & $<0.001$ & $7.5(2.2-25.7)$ & 0.001 \\
\hline 30-d mortality & 0 & $1(1)$ & $2(2)$ & Not applicable & $1.000 \S$ & $0.3(0-3.0)$ & 0.287 & Not applicable & $1.000 \pi$ \\
\hline \multicolumn{10}{|c|}{$\begin{array}{l}\text { *ALT, alanine aminotransferase; AST, aspartate aminotransferase; BT, body temperature; BUN, blood urea nitrogen; CRP, C-reactive protein; DOXY, } \\
\text { doxycycline; F, female patients; Hb, hemoglobin; JSF, Japanese spotted fever; LDH, lactate dehydrogenase; M, male patients; MINO, minocycline; non-R, } \\
\text { nonrickettsial diseases; OR, odds ratio; ST, scrub typhus. } \\
\text { †Non-R = reference. } \\
\text { †ST = reference. } \\
\text { §Duration from the onset of symptoms to the first diagnostic test. } \\
\text { TFisher exact tests. } \\
\#>3 \text { d to decline of fever }<37.3^{\circ} \mathrm{C} \text {. }\end{array}$} \\
\hline
\end{tabular}

JSF and ST for patients for whom convalescent-phase samples were unavailable. To determine the optimum cutoff titer in our setting, we collected blood samples from patients with nonrickettsial diseases and confirmed that the highest IgM titer for $R$. japonica was $<20$ and that for O. tsutsugamushi was 10 (online Technical Appendix Table 2). Therefore, our diagnostic criteria must be very specific.

During the acute phase of the disease, sensitivity of the IFA is quite low; in our study, an elevated IgM titer by IFA was observed in the acute-phase samples of only $2(6.5 \%)$ of 31 patients with JSF and 73 (38.8\%) of 188 patients with ST. Hence, physicians may overlook these diseases if their diagnosis relies on IgM titer by IFA during the early phase. Furthermore, the ST serotypes affect the sensitivity of the IFA. In our study, of the 22 patients for whom serotype was identified, 16 serotypes were Irie/Kawasaki and 6 serotypes were Hirano/Kuroki. In Japan, health insurance covers IFAs for the standard serotypes Kato, Karp, and Gilliam only but not for serotypes Irie/Kawasaki and Hirano/ Kuroki, which may not be cross-reactive to the standard serotypes (22). In our study population, use of IFAs to test for the standard serotypes could have led to underdiagnosis of ST for $\approx 5 \%$ of the patients because 2 patients with the Irie/Kawasaki and Hirano/Kuroki serotypes did not react to any of the standard serotypes. 
Our study has limitations because we did not include the other 2 hospitals in the southern Boso Peninsula. However, our study sites are the only medical facilities in the district that have infectious disease specialists. Most patients with acute disease and fever in this district are expected to visit our clinic and hospitals. Thus, we believe that the effect of selection bias was minimal. Because our study is a combined prospective and retrospective case-series, the quality of the information may have differed between the prospectively and the retrospectively identified patients. However, we used an identical case definition throughout the study, and further analyses indicated that the clinical and epidemiologic characteristics did not differ between 2 groups (online Technical Appendix Table 3).

In conclusion, although JSF and ST share similar clinical features, in Japan the 2 diseases differ in seasonality, geographic distribution, physical signs, and severity. Patients with rickettsial diseases often do not notice their rash and eschar, and the sensitivity of the serologic test can be low during the acute phase of illness. A substantial number of rickettsial diseases may be underdiagnosed.

\section{Acknowledgments}

We thank the clinical laboratory staff at Kameda Medical Center and Takeshi Kimura and Yasuhisa Matsushita for collecting the data at the Awa Regional Medical Center.

This study was funded by the Kameda Medical Center; grants from the Japan Ministry of Health, Labour and Welfare (H21-Shinkou-Ippan-006 and H24-Shinkou-Ippan-008); and Grants-in-Aid for Scientific Research (Japan Society for the Promotion of Science).

\section{About the Author}

Dr. Sando is a general physician at Kameda Medical Center, Kamogawa, Japan, and a postgraduate at Nagasaki University Graduate School of Biomedical Sciences, Nagasaki, Japan. His primary research interests include rickettsial diseases such as ST and JSF.

\section{References}

1. Blake FG, Maxcy KF, Sadusk JF Jr, Kohls GM, Bell EJ. Studies on tsutsugamushi disease (scrub typhus, mite-borne typhus) in New Guinea and adjacent islands: epidemiology, clinical observations, and etiology in the Dobadura Area. Am J Hyg. 1945;41:245-6.

2. Nagino T, Kawakami S. Review: a disease caused by poisonous insect [in Japanese]. Tokyo Medical Journal. 1878;20:3-7.

3. National Institute of Infectious Diseases-Japan. Scrub typhus and Japanese spotted fever in Japan 2007-2016. Infectious Agent Surveillance Report. Tokyo: The Institute; 2017. p. 109-12.

4. Maina AN, Farris CM, Odhiambo A, Jiang J, Laktabai J, Armstrong J, et al. Q fever, scrub typhus, and rickettsial diseases in children, Kenya, 2011-2012. Emerg Infect Dis. 2016;22:883-6. http://dx.doi.org/10.3201/eid2205.150953

5. Weitzel T, Dittrich S, López J, Phuklia W, Martinez-Valdebenito C, Velásquez K, et al. Endemic scrub typhus in South America. N Engl J Med. 2016;375:954-61. http://dx.doi.org/10.1056/ NEJMoa1603657

6. Mahara F, Koga K, Sawada S, Taniguchi T, Shigemi F, Suto T, et al. The first report of the rickettsial infections of spotted fever group in Japan: three clinical cases [in Japanese]. Kansenshogaku Zasshi. 1985;59:1165-71. http://dx.doi.org/10.11150/ kansenshogakuzasshi1970.59.1165

7. Takada N, Fujita H, Yano Y, Oikawa Y, Mahara F. Vectors of Japanese spotted fever [in Japanese]. Kansenshogaku Zasshi. 1992;66:1218-25. http://dx.doi.org/10.11150/ kansenshogakuzasshi1970.66.1218

8. Chung MH, Lee SH, Kim MJ, Lee JH, Kim ES, Kim MK, et al. Japanese spotted fever, South Korea. Emerg Infect Dis. 2006;12:1122-4. http://dx.doi.org/10.3201/eid1207.051372

9. Hamaguchi S, Cuong NC, Tra DT, Doan YH, Shimizu K, Tuan NQ, et al. Clinical and epidemiological characteristics of scrub typhus and murine typhus among hospitalized patients with acute undifferentiated fever in Northern Vietnam. Am J Trop Med Hyg. 2015;92:972-8. http://dx.doi.org/10.4269/ ajtmh.14-0806

10. Su TH, Liu CJ, Chen DS, Kao JH. Milder clinical manifestation of scrub typhus in Kinmen, Taiwan. J Formos Med Assoc. 2013;112:201-7. http://dx.doi.org/10.1016/j.jfma.2012.02.002

11. Sharma N, Biswal M, Kumar A, Zaman K, Jain S, Bhalla A. Scrub typhus in a tertiary care hospital in north India. Am J Trop Med Hyg. 2016;95:447-51. http://dx.doi.org/10.4269/ ajtmh.16-0086

12. Park JH, Kim SJ, Youn SK, Park K, Gwack J. Epidemiology of scrub typhus and the eschars patterns in South Korea from 2008 to 2012. Jpn J Infect Dis. 2014;67:458-63. http://dx.doi.org/10.7883/ yoken.67.458

13. Ogawa M, Hagiwara T, Kishimoto T, Shiga S, Yoshida Y, Furuya Y, et al. Scrub typhus in Japan: epidemiology and clinical features of cases reported in 1998. Am J Trop Med Hyg. 2002;67:162-5. http://dx.doi.org/10.4269/ajtmh.2002.67.162

14. Kodama K, Senba T, Yamauchi H, Nomura T, Chikahira Y. Clinical study of Japanese spotted fever and its aggravating factors. J Infect Chemother. 2003;9:83-7. http://dx.doi. org/10.1007/s10156-002-0223-5

15. Yasunaga H, Horiguchi $\mathrm{H}$, Kuwabara K, Hashimoto H, Matsuda $\mathrm{S}$. Delay in tetracycline treatment increases the risk of complications in tsutsugamushi disease: data from the Japanese Diagnosis Procedure Combination database. Intern Med. 2011;50:37-42. http://dx.doi.org/10.2169/internalmedicine.50.4220

16. Nakamura T, Takagaki K, Matsubara Y, Kikuchi K. Predictive values of clinical parameters for severe Japanese spotted fever. J Infect Chemother. 2011;17:246-53. http://dx.doi.org/10.1007/ s10156-010-0113-1

17. Tai K, Iwasaki H, Ikegaya S, Takada N, Tamaki Y, Tabara K, et al. Significantly higher cytokine and chemokine levels in patients with Japanese spotted fever than in those with tsutsugamushi disease. J Clin Microbiol. 2014;52:1938-46. http://dx.doi.org/10.1128/ JCM.03238-13

18. Fujita H. Development and optimization of antibody detection assays. In: Ando S, editor. Diagnostics and Therapeutics for Tick-Borne Bacterial Diseases. MHLW Grant Research Report 201225058A [in Japanese]. Tokyo (Japan): Ministry of Health, Labour and Welfare; 2012. p. 95-100.

19. Furuya Y, Yoshida Y, Katayama T, Yamamoto S, Kawamura A Jr. Serotype-specific amplification of Rickettsia tsutsugamushi DNA by nested polymerase chain reaction. J Clin Microbiol. 1993; 31:1637-40. 
20. Furuya Y, Katayama T, Yoshida Y, Kaiho I. Specific amplification of Rickettsia japonica DNA from clinical specimens by PCR. J Clin Microbiol. 1995;33:487-9.

21. Kulldorff M. A spatial scan statistic. Commun Stat Theory Methods. 2007;26:1481-96. http://dx.doi.org/10.1080/03610929708831995

22. National Institute of Infectious Diseases-Japan. The topic of this month. Infectious Agent Surveillance Report (IASR). Tokyo: The Institute; 2001. p. 211-2.

23. Mori K, Fujimagari M. Distribution and seasonal fluctuation of ticks in Chiba. Chiba Prefectural Institute of Public Health Research Report. Chiba (Japan): Chiba Prefectural Institute of Public Health; 1994. p. 53-8

24. Suzuki T, Nanayama Y, Sasa M, Tanaka H, Hayashi S, Suzuki T, et al. Studies on scrub typhus in Chiba Prefecture. V: seasonal occurrence of the trombiculid mites in southern part of Boso Peninsula. Medical Entomology and Zoology. 1955;6:69-75. http://dx.doi.org/10.7601/mez.6.69

25. Tsukada H, Nakamura Y, Kamio T, Inokuma H, Hanafusa $Y$, Matsuda N, et al. Higher sika deer density is associated with higher local abundance of Haemaphysalis longicornis nymphs and adults but not larvae in central Japan. Bull Entomol Res. 2014;104:19-28. http://dx.doi.org/10.1017/S0007485313000308

26. Asada M. Distribution and population estimation for Sika deer in 2010 in Chiba Prefecture, Japan. Chiba (Japan); Chiba Biodiversity Center; 2011. p. 16-7.

27. Asada M. Distribution and population estimation for Reeves's muntjac in 2010 in Chiba Prefecture, Japan. Chiba (Japan); Chiba Biodiversity Center; 2011. p. 36-43.

28. Gokuden M, Ishitani K, Yoshikuni K, Ueno N, Shinkawa N, Kuramoto T, et al. Epidemiology of tsutsugamushi disease and Japanese spotted fever in Kagoshima Prefecture, Japan. Jpn J Infect Dis. 2006;59:273.

29. Tabara K, Hoshina K, Itagaki A, Katayama T, Fujita H, Kadosaka T, et al. Epidemiological study of Japanese spotted fever and tsutsugamushi disease in Shimane Prefecture, Japan. Jpn J Infect Dis. 2006;59:204-5.

30. Paris DH, Day NP. Tropical rickettsial infections. In: Farrer J, Hotez PJ, Kang G, Lalloo D, White NJ, editors. Manson's Tropical Diseases. 23rd ed. New York: Elsevier; 2014. p. 273-91.

31. Walker DH. Rickettsiae and rickettsial infections: the current state of knowledge. Clin Infect Dis. 2007;45(Suppl 1):S39-44. http://dx.doi.org/10.1086/518145

32. Paris DH, Stephan F, Bulder I, Wouters D, van der Poll T, Newton PN, et al. Increased nucleosomes and neutrophil activation link to disease progression in patients with scrub typhus but not murine typhus in Laos. PLoS Negl Trop Dis. 2015;9:e003990. http://dx.doi.org/10.1371/journal.pntd.0003990

33. Taylor AJ, Paris DH, Newton PN. A systematic review of mortality from untreated scrub typhus (Orientia tsutsugamushi). PLoS Negl Trop Dis. 2015;9:e0003971. http://dx.doi.org/10.1371/ journal.pntd.0003971

34. Matsui T, Kobayashi J, Satoh H, Fujimoto T, Okabe N, Ando S, et al. Surveillance, recognition, and reporting of tsutsugamushi disease (scrub typhus) and Japanese spotted fever by general practice clinics in Miyazaki Prefecture, determined by questionnaire survey in 2007. J Infect Chemother. 2009;15:269-72. http://dx.doi.org/10.1007/s10156-009-0696-6

35. Blacksell SD, Bryant NJ, Paris DH, Doust JA, Sakoda Y, Day NP. Scrub typhus serologic testing with the indirect immunofluorescence method as a diagnostic gold standard: a lack of consensus leads to a lot of confusion. Clin Infect Dis. 2007;44:391-401. http://dx.doi.org/10.1086/510585

Address for correspondence: Motoi Suzuki, Nagasaki University,

Department of Clinical Medicine, Institute of Tropical Medicine, Sakamoto

1-12-4, Nagasaki, 852-8523, Japan; email: mosuzuki@nagasaki-u.ac.jp

\section{May 2016: Vectorborne Diseases}

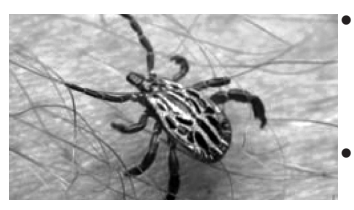

- An Operational Framework for Insecticide Resistance Management Planning

- Rickettsia parkeri Rickettsiosis, Arizona, USA

- Plasmodium falciparum K76T pfcrt Gene Mutations and Parasite Population Structure, Haiti, 2006-2009

- Outbreak of Middle East Respiratory Syndrome at Tertiary Care Hospital, Jeddah, Saudi Arabia, 2014

- Expansion of Shiga Toxin-Producing Escherichia coli by Use of Bovine Antibiotic Growth Promoters

- Acute Human Inkoo and Chatanga Virus Infections, Finland

- Differences in Genotype, Clinical Features, and Inflammatory Potential of Borrelia burgdorferi sensu stricto Strains from Europe and the United States

- Projecting Month of Birth for At-Risk Infants after Zika Virus Disease Outbreaks

- Genetic Characterization of Archived Bunyaviruses and Their Potential for Emergence in Australia

- Plasmodium falciparum In Vitro Resistance to Monodesethylamodiaquine, Dakar, Senegal, 2014

- Astrovirus MLB2, a New Gastroenteric Virus Associated with Meningitis and Disseminated Infection

- Spectrum of Viral Pathogens in Blood of Malaria-Free III Travelers Returning to Canada

- Expanded Geographic Distribution and Clinical Characteristics of Ehrlichia ewingii Infections, United States

- Molecular Characterization of Canine Rabies Virus, Mali, 2006-2013

- Fatal Monocytic Ehrlichiosis in Woman, Mexico, 2013

- Rickettsia sibirica mongolitimonae Infection, France, 2010-2014

https://wwwnc.colc.gov/eid/articles/ issue/22/5/table-of-contents EMERGNG INFECTIOUS DISEASES 